CLINICAL STUDY

\title{
Bone quality, as measured by trabecular bone score, in patients with primary hyperparathyroidism
}

\author{
Cristina Eller-Vainicher, Marcello Filopanti, Serena Palmieri, Fabio Massimo Ulivieri ${ }^{1}$, Valentina Morelli, \\ Volha V Zhukouskaya, Elisa Cairoli, Rosa Pino ${ }^{1}$, Antonella Naccarato ${ }^{1}$, Uberta Verga, Alfredo Scillitani ${ }^{2}$, \\ Paolo Beck-Peccoz and Iacopo Chiodini \\ Unit of Endocrinology and ${ }^{1}$ Nuclear Medicine, Fondazione IRCCS Cà Granda-Ospedale Maggiore Policlinico, Department of Clinical Sciences and \\ Community Health, University of Milan, Milan, Italy and ${ }^{2}$ Unit of Endocrinology, 'Casa Sollievo della Sofferenza', IRCCS, San Giovanni Rotondo, Foggia, \\ Italy \\ (Correspondence should be addressed to I Chiodini who is now at Endocrinology and Diabetology Unit, Padiglione Granelli, Via Francesco Sforza 35,20122 \\ Milan, Italy; Email: iacopo.chiodini@policlinico.mi.it)
}

\begin{abstract}
Objective: In primary hyperparathyroidism (PHPT), vertebral fractures (VFx) occur regardless of bone mineral density (BMD) and may depend on decreased bone quality. Trabecular bone score (TBS) is a texture measurement acquired during a spinal dual-energy X-ray absorptiometry (DXA). Recently, TBS has been proposed as an index of bone micro-architecture.

Design: We studied 92 PHPT patients ( 74 females, age $62.1 \pm 9.7$ years) and 98 control subjects. In all patients at baseline, in 20 surgically treated patients and in 10 conservatively treated patients after 24 months, TBS, spinal (lumbar spine (LS)) and femoral (total hip (TH) and femoral neck (FN)) BMD were assessed by DXA and VFx by spinal radiograph.

Results: PHPT patients had lower TBS $(-2.39 \pm 1.8)$ and higher VFx prevalence $(43.5 \%)$ than controls $(-0.98 \pm 1.07$ and $8.2 \%$ respectively, both $P<0.0001)$. TBS was associated with VFx (odds ratio 1.4 , 95\% CI 1.1-1.9, $P=0.02$ ), regardless of LS-BMD, age, BMI and gender, and showed a better compromise between sensitivity $(75 \%)$ and specificity $(61.5 \%)$ for detecting VFx than LS-BMD, TH-BMD and FN-BMD (31 and 75\%, 72 and 44.2\%, and 64 and $65 \%$ respectively). In surgically treated patients, TBS, LS-BMD, TH-BMD and FN-BMD increased $(+47 \pm 44.8,+29.2$ $\pm 34.1,+49.4 \pm 48.7$ and $+30.2 \pm 39.3 \%$ respectively, all $P<0.0001)$. Among patients treated conservatively, TBS decreased significantly in those $(n=3)$ with incident VFx $(-1.3 \pm 0.3)$ compared with those without $(-0.01 \pm 0.9, P=0.048)$, while BMD changes were not statistically different (LS $0.3 \pm 1.2$ vs $-0.8 \pm 0.9$ respectively, $P=0.19$; TH $0.4 \pm 0.8$ vs $-0.8 \pm 1.4$ respectively, $P=0.13$ and FN $0.4 \pm 0.9$ vs $-0.8 \pm 1.4$ respectively, $P=0.14$ ).

Conclusions: In PHPT, bone quality, as measured by TBS, is reduced and associated with VFx and improves after surgery.
\end{abstract}

European Journal of Endocrinology 169 155-162

\section{Introduction}

Primary hyperparathyroidism (PHPT) is a common endocrine disease with a prevalence of $3 \%$ in the general population (1) and of 2.5-3\% in women $>65$ years of age (2). It is known that PHPT leads to bone loss and increased fracture risk, which are particularly pronounced at sites rich in cortical bone $(3,4,5,6)$. Despite the preferential involvement of cortical bone in PHPT, an increased rate of vertebral fractures $(\mathrm{VFx})$ has been reported in patients with $\mathrm{PHPT}(7,8,9)$. In these subjects, the evaluation of bone mineral density (BMD) at the spine does not reliably mirror the increased risk of fractures $(8,9)$, and a deterioration of bone quality (trabecular number, thickness and connectivity) has been advocated as a contributor to the increased VFx risk (10).
To date, bone micro-architecture can be directly assessed only by histomorphometric or microCT analysis of an invasively obtained bone biopsy sample or by high-resolution peripheral quantitative computed tomography $(11,12)$, which is, however, impractical for routine clinical management.

The trabecular bone score (TBS) is a grey-level texture measurement based on the use of experimental variograms of two-dimensional (2D) projection images acquired during a dual-energy X-ray absorptiometry (DXA) lumbar spine (LS) scan (13). It may be used for the routine evaluation of bone micro-architecture, as it is strongly correlated with bone micro-architecture, regardless of BMD $(14,15)$. Several studies suggested the usefulness of TBS in addition to BMD to identify patients with postmenopausal osteoporosis at higher 
risk of fracture $(16,17,18,19,20)$. In addition, TBS has been documented to be useful as an adjunctive tool in assessing the risk of fracture in patients with secondary forms of osteoporosis $(21,22)$, which are typically characterized by a reduction of bone quality (23).

Recently, TBS has been found to be more accurate than spinal BMD for identifying PHPT patients at risk for VFx (24) and to be associated with trabecular microarchitecture as assessed by high-resolution peripheral quantitative computed tomography (25).

Therefore, the aim of this study was to evaluate the usefulness of TBS alone or in combination with BMD for predicting VFx in PHPT patients before and after surgery or a conservative follow-up.

\section{Subjects and methods}

\section{Subjects}

This prospective observational study was performed at 'Fondazione IRCCS Cà Granda' (Milan). From January 2010 to December 2011, 92 Caucasian patients (74 postmenopausal females and 18 eugonadal males) with PHPT were consecutively enrolled.

PHPT was diagnosed in the presence of hypercalcaemia and elevated or inappropriately normal parathyroid hormone (PTH) levels, after the exclusion of a familial hypocalciuric hypercalcaemia by the evaluation of calcium clearance:creatinine clearance ratio in the presence of normal renal function (26). The exclusion criteria were i) past or current history of hypogonadism (in males, testosterone levels $<3.0 \mathrm{ng} / \mathrm{ml}$ in two different samples; in females, occurrence of menopause before 45 years) and of other diseases known to affect bone metabolism (i.e. thyrotoxicosis, bowel diseases, chronic renal failure, chronic hepatic disease, depression, alcoholism, eating disorders and rheumatological or haematological diseases); ii) administration of drugs influencing bone metabolism or PTH and calcium levels; iii) the presence of multiple endocrine neoplasia type 1 syndrome, as in this condition, the clinical presentation may be different compared with sporadic PHPT (27) and iv) history of a possible highenergy VFx.

Ninety-eight subjects (81 postmenopausal females and 17 eugonadal males) served as controls. These subjects were consecutively enrolled on the basis of the above-mentioned exclusion criteria from our outpatient clinics at which they were referred for unrelated diseases (multinodular goitre with normal thyroid function). In all control subjects with low BMD, a routine screening was performed to exclude patients with secondary osteoporosis in accordance with the Italian Society for Osteoporosis, Mineral Metabolism and Bone Diseases guidelines (28).

Among the whole group of PHPT patients, we also report the available longitudinal data of 20 subjects
(19 females) after 24 months from surgery and recovery from PHPT and of 10 subjects after 24 months of a conservative follow-up. These subjects have been consecutively included in an ongoing study protocol aimed to assess the value of TBS in predicting the incidence of fracture in PHPT patients. None of these subjects took drugs that could interfere with skeletal status.

Among these patients, surgery was not indicated in seven subjects (25) on the basis of the criteria from the 3rd International Workshop on asymptomatic PHPT (26), and it was refused in three patients. All surgically treated patients had verified parathyroid adenomas and/or hyperplasia and their calcium and PTH levels normalized after surgery.

All subjects gave their witnessed informed consent before entering the study, which was approved by Local Ethics Committees and in accordance with Helsinki Declaration II.

\section{Methods}

Serum and urinary samples were collected and stored at $-20{ }^{\circ} \mathrm{C}$ until assayed. In all subjects, the following was measured: blood cell count, serum calcium, creatinine, intact PTH, 25-hydroxyvitamin D (250HVitD), protein electrophoresis and total testosterone (in males). Total calcium was corrected for serum albumin according to the formula: (total calcium $+(4.4-$ albumin $\mathrm{mg} / \mathrm{dl}) \times 0.8) \quad($ reference interval $8.4-10.4 \mathrm{mg} / \mathrm{dl}$, $2.1-2.5 \mathrm{mmol} / \mathrm{l}$ ) (29). Urinary calcium and creatinine were measured in 24-h urine collections and calcium clearance was calculated in order to exclude the presence of benign hypocalciuric hypercalcaemia.

Calcium, albumin, and creatinine in serum and urinary calcium and creatinine were measured by standard colorimetric techniques. Serum intact PTH was measured by a chemiluminescent method (Nichols Institute Diagnostic, San Juan Capistrano, CA, USA) with intra- and interassay coefficient of variation (CV) of 5.1 and $8.2 \%$ respectively. Serum $250 H V i t D$ levels were measured by RIA (DiaSorin, Saluggia, Italy) with an intra- and interassay CV of 5.6 and $15 \%$ respectively.

At the enrolment, all patients and controls with $250 H V i t D$ levels $<75 \mathrm{nmol} / \mathrm{l}$ received cholecalciferol supplementation. An oral bolus of 100000 or $300000 \mathrm{IU}$ of cholecalciferol was administered in patients with $250 H V i t D$ levels between 25 and $72.5 \mathrm{nmol} / \mathrm{l}$, and $<25 \mathrm{nmol} / \mathrm{l}$ respectively (28). All patients included in the longitudinal arms of the study received cholecalciferol supplementation throughout the 24 months of follow-up, in order to maintain $250 H V i t D$ levels above $75 \mathrm{nmol} / \mathrm{l}$.

At the enrolment, in all patients and controls, BMD was measured by DXA (Hologic Discovery, Software version 13.3:3, Bedford MA, USA) at LS (precision $1.0 \%$ ), total hip (TH, precision $1.7 \%$ ) and femoral neck 
(FN, precision 1.8\%). Individual BMD values were expressed as s.D. units ( $Z$ values) in relation to reference population (30). Fractured vertebrae were excluded from BMD measurement.

At the enrolment, in all patients, conventional spinal radiographs (T4-L4) in lateral and antero-posterior projection were obtained with standardized technique in all subjects. Two trained physicians, who were blinded to BMD and hormonal data, independently reviewed the radiographs. The radiologists discussed questionable cases to agree on a diagnosis. VFx were diagnosed on visual inspection using the semiquantitative (SQ) visual assessment, previously described by Genant et al. (31). According to this technique, fractures assessed on lateral thoraco-LS radiographs were defined as reductions of more than $20 \%$ in anterior, middle or posterior vertebral height. From lateral spine radiographs, each vertebra is visually assessed as intact (SQ grade 0) or as having approximately mild (20-25\% compression), moderate (25-40\% compression) or severe ( $>40 \%$ compression) deformity (SQ grades 1, 2 and 3 respectively). Subsequently, for each subject, the spinal deformity index (SDI) was calculated by summing the SQ grade for each of the 13 vertebrae from T4 to L4 $(\mathrm{SDI}=\mathrm{SQT} 4+\ldots+\mathrm{SQT} 12+\mathrm{SQL} 1+\ldots+\mathrm{SQL} 4)(32,33)$.

In all patients and controls, TBS was assessed in the region of LS-BMD according to previously described methods (22). Briefly, the TBS is a grey-level texture measurement based on the use of experimental variograms of $2 \mathrm{D}$ projection images acquired during a LS scan. An empirical 3D/2D relationship has been established that expresses the TBS as a function of two 3D bone characteristics: solid volume fraction and mean solid thickness (15). TBS is able to differentiate between two 3D micro-architectures that exhibit the same bone density, with different trabecular characteristics. This evaluation is constrained by neither the size nor the shape of the region being measured. TBS is, therefore, a texture measurement for small and/or irregular surfaces of analysis, such as the standard region of measurement defined in DXA images. Higher TBS may reflect strong, fracture-resistant micro-architecture, whereas a low TBS may reflect weak, fracture-prone micro-architecture $(16,18)$. In order to normalize TBS values for age, TBS data were reported as S.D. units (Z-scores) in relation to the French reference population (34).

\section{Statistical analysis}

Statistical analysis was performed by SPSS version 12.0 statistical package (SPSS, Inc.). The results are expressed as mean \pm s.D. The normality of distribution was tested by Kolmogorov-Smirnov test.

The comparison of continuous variables between PHPT patients and controls was performed using Student's $t$-test or Mann-Whitney U test as appropriate.
Categorical variables were compared by $\chi^{2}$ test or by Fisher exact test as appropriate. The associations between the calcium metabolism parameters, TBS, age, years since menopause, SDI and LS-BMD, FN-BMD and TH-BMD were tested by either Pearson's product-moment correlation or Spearman's correlation as appropriate.

The logistic regression analysis assessed in PHPT patients the association between the presence of a prevalent fracture (dependent variables, expressed as categorical variables) and TBS after adjusting for the following independent variables: age or years since menopause, BMI, gender and LS-BMD.

The receiver operating characteristic (ROC) curve analysis was performed to assess the best cut-offs of TBS and LS-BMD, TH-BMD and FN-BMD for detecting PHPT patients with prevalent VFx. On the basis of these cut-offs, sensitivity (SN), specificity (SP) and overall accuracy of TBS, LS-BMD, TH-BMD and FN-BMD and of the combinations low TBS plus low BMD (at LS or TH or FN or at any site) and of low TBS or low BMD (at LS or $\mathrm{TH}$ or $\mathrm{FN}$ or at any site) were calculated. $P$ values of $<0.05$ were considered significant.

\section{Results \\ Cross-sectional arm of the study: comparison between PHPT patients and controls}

The clinical and biochemical characteristic of patients and controls before 250HVitD level normalization are reported in Table 1. Age, BMI, years since menopause, gender and 250HVitD levels were not different between PHPT patients and controls. Patients showed lower TBS, LS-BMD, TH-BMD and FN-BMD levels and higher SDI and prevalence of VFx.

\section{Accuracy of TBS, LS-BMD, TH-BMD and FN-BMD in detecting PHPT patients with VFx}

The bivariate correlation analysis showed that TBS was associated with LS-BMD $(r=0.27, P=0.011)$ and SDI ( $R=-0.31, P=0.003)$ but not with any parameter of calcium metabolism, BMI or years since menopause. The logistic regression analysis showed that the presence of a VFx was associated with TBS (odds ratio (OR) $1.4,95 \%$ CI $1.1-1.9, P=0.02)$, regardless of LS-BMD (OR 1.2, 95\% CI 0.7-1.9, $P=0.52)$, age (OR 1.0, 95\% CI 0.9-1.1, P=0.11), BMI (OR 1.0, 95\% CI 0.9-1.2, $P=0.6$ ) and gender (OR 2.9, 95\% CI $0.8-11.1, P=0.12)$. The same analysis showed that the number of years since menopause was not associated with VFx and did not modify the results (TBS OR 1.6, 95\% CI 1.21-2.2, $P=0.001$; LS-BMD OR 1.8, 95\% CI $1.1-2.9, P=0.015$; years since menopause OR 1.0 95\% CI $0.9-1.1, P=0.147$; BMI OR $1.0,95 \%$ CI $0.9-1.1, P=0.512)$. 
Table 1 Clinical and biochemical characteristics of patients with PHPT and control subjects. Data are mean \pm s.D. with range in parenthesis or absolute number with percentage in parenthesis. The data reported are obtained before cholecalciferol supplementation.

\begin{tabular}{|c|c|c|c|}
\hline & Controls $(n=98)$ & PHPT $(n=92)$ & $\boldsymbol{P}$ \\
\hline Age (years) & $62.1 \pm 9.7(45.6$ to 80.0$)$ & $62.7 \pm 10.1(40.0$ to 82.0$)$ & 0.670 \\
\hline BMI $\left(\mathrm{kg} / \mathrm{m}^{2}\right)$ & $27.0 \pm 3.8(20.5$ to 36.4$)$ & $26.2 \pm 4.5(19.0$ to 35.0$)$ & 0.253 \\
\hline Females/males & $81 / 17(82.7 / 17.3)$ & $74 / 18(80.4 / 19.6)$ & 0.712 \\
\hline YSM (years) & $13.6 \pm 9.2(1.0$ to 33.0$)$ & $13.5 \pm 8.6(1.0$ to 31.5$)$ & 0.99 \\
\hline 25-Hydroxyvitamin $\mathrm{D}(\mathrm{nmol} / \mathrm{l})$ & $69 \pm 23$ (41.3 to 164.5$)$ & $71 \pm 29.3$ (37 to 157.5$)$ & 0.631 \\
\hline PTH (ng/l) & $48.4 \pm 14.4(16.1$ to 79$)$ & $151.5 \pm 105.9(42$ to 638$)$ & $<0.0001$ \\
\hline Serum calcium $(\mathrm{mmol} / \mathrm{l})$ & $2.3 \pm 0.1(2.1$ to 2.6$)$ & $2.8 \pm 0.2$ (2.6 to 3.9$)$ & $<0.0001$ \\
\hline $\begin{array}{l}\text { No. of patients with calcium } \\
>2.85 \mathrm{mmol} / \mathrm{l}^{\mathrm{a}}\end{array}$ & -1 & $32(34.8)$ & - \\
\hline Urinary calcium 24 h (mmol/day) & $4.2 \pm 1.8(1.8$ to 8$)$ & $8.1 \pm 4.4(2.5$ to 28$)$ & $<0.0001$ \\
\hline Urinary calcium $24 \mathrm{~h} / \mathrm{kg}$ (mmol/day) & $0.06 \pm 0.03(0.03$ to 0.1$)$ & $0.12 \pm 0.06(0.03$ to 0.4$)$ & $<0.0001$ \\
\hline Creatinine clearance $(\mathrm{ml} / \mathrm{min})$ & - & $88.2 \pm 22.3(50$ to 144$)$ & - \\
\hline $\begin{array}{l}\text { No. of patients with creatinine clearance } \\
<60 \mathrm{ml} / \mathrm{min}\end{array}$ & - & $11(12)$ & - \\
\hline LS-BMD (Z-score) & $0.51 \pm 1.46(-2.00$ to 4.10$)$ & $-0.73 \pm 1.14(-3.80$ to 2.80$)$ & $<0.0001$ \\
\hline TH-BMD (Z-score) & $0.22 \pm 0.83(-1.50$ to 2.10$)$ & $-0.48 \pm 0.93(-2.50$ to 1.40$)$ & $<0.0001$ \\
\hline FN-BMD (Z-score) & $0.05 \pm 0.85(-2.60$ to 2.70$)$ & $-0.69 \pm 0.84(-2.50$ to 1.90$)$ & $<0.0001$ \\
\hline TBS (Z-score) & $-0.98 \pm 1.07(-2.51$ to 1.99$)$ & $-2.39 \pm 1.79(-6.55$ to 1.97$)$ & $<0.0001$ \\
\hline No. of patients with vertebral fractures & $8(8.2)$ & $40(43.5)$ & $<0.0001$ \\
\hline SDI & $0.09 \pm 0.32(0$ to 2$)$ & $1.03 \pm 1.79(0$ to 9$)$ & $<0.0001$ \\
\hline No. of patients with nephrolithiasis & - & $44(47.8)$ & - \\
\hline
\end{tabular}

BMD, bone mineral density; LS, lumbar spine; TH, total femur; FN, femoral neck; TBS, trabecular bone score; SDI, spinal deformity index, sum of the fracture grades of all vertebrae (T4-L4), assigning for each vertebra a visual semiquantitative grades of $0,1,2$ or 3 for no fracture or mild, moderate or severe fracture respectively; PTH, parathyroid hormone. Urinary calcium $24 \mathrm{~h} / \mathrm{kg}$, urinary calcium $24 \mathrm{~h}$ corrected for weight; YSM, years since menopause.

${ }^{\mathrm{a}} 0.25 \mathrm{mmol} / \mathrm{l}$ above the upper normal limit.

The ROC analysis, performed to assess the best threshold values of TBS, LS-BMD, TH-BMD and FN-BMD for predicting VFx, showed that TBS, LS-BMD, TH-BMD and FN-BMD have a moderate accuracy for predicting VFx (area under the ROC curve $0.74,0.7,0.67$ and 0.71 respectively, $P<0.0001$ for all analyses). The cut-offs with the best compromise between SN and SP were set at -2.1 for TBS, -0.3 for LS-BMD, -0.2 for TH-BMD and -0.6 for FN-BMD (expressed as Z-scores). The SN, SP and overall accuracy for predicting VFx of low TBS (i.e. $<-2.1$ ), low LS-BMD (i.e. $<-0.3$ ), low TH-BMD (i.e. $<-0.2$ ), low FN-BMD (i.e. $<-0.6$ ); of the combinations low TBS plus low LS-BMD or TH-BMD or FN-BMD or low BMD at any site; and of the combinations low TBS or low LS-BMD, or TH-BMD or FN-BMD or low BMD at any site are reported in Table 2. Low TBS showed higher accuracy than low LS-BMD, TH-BMD and FN-BMD for detecting patients with fractures. However, compared with TBS alone, the combination low TBS plus low FN-BMD had higher SP and slightly higher accuracy, but lower SN for detecting patients with VFx. The presence of the combinations low TBS or low TH-BMD and low TBS or low FN-BMD showed a 95\% SN, but a 23.1 and a $28.8 \%$ SP respectively, for detecting patients at risk of fractures (Table 2). Indeed, only two of the 40 PHPT patients with fractures did not show low TBS and/or low FN-BMD (false negative), but, on the other hand, 37 out of the 52 patients without VFx showed, in fact, low TBS and/or low FN-BMD, being, therefore, false positive (Fig. 1).

\section{Longitudinal arm of the study: effect of surgical and conservative treatment on TBS, BMD and VFx in PHPT patients}

The biochemical and clinical characteristics at baseline and after 24 months of follow-up of the 20 patients operated on (19 females and one male, surgical group) and the ten patients conservatively treated (seven females and three males, conservative group) are reported in Table 3.

In the surgical group, no patient experienced new VFx and, after 24 months, BMD (at both spine and femur) improved and TBS increased significantly, although still remaining lower compared with controls (Fig. 2). The mean Z-scores increase was higher for TBS $(1.2 \pm 1.6)$ compared with LS $(0.4 \pm 0.7, P=0.026)$, TH $(0.1 \pm 0.9, P=0.01)$ and $\mathrm{FN}(0.1 \pm 0.9, P=0.01)$, while it was comparable among LS, TH and FN.

In the conservative group, three subjects experienced a new VFx, BMD remained stable at spine (mean Z-score decrease $-0.01 \pm 1.2$ ) and femur (mean Z-score decrease TH $0.03 \pm 1.1$, FN $0.01 \pm 1.1$ ), while mean TBS values decreased $(-0.4 \pm 0.97)$, even if without reaching the statistical significance (Fig. 2). In the three patients experiencing a VFx during the follow-up, TBS significantly decreased $(-1.3 \pm 0.3)$ as compared with the seven patients without a new $\operatorname{VFx}(-0.01 \pm 0.9, P=0.048)$. At variance, the BMD decrease was not statistically different between conservatively treated patients with and without a new VFx (LS $-0.8 \pm 0.9$ vs $0.3 \pm 1.2$ respectively, $P=0.19 ; \mathrm{TH}-0.8 \pm 1.4$ vs $0.4 \pm 0.8$ respectively, 
Table 2 Diagnostic accuracy of low TBS and low BMD (at spine and/or femur), taken alone or in combination, for detecting PHPT patients with prevalent vertebral fracture. Data are expressed as percentage. Low TBS and low BMD were defined on the basis of the cut-offs obtained by ROC analysis (see text). These cut-offs represent the best compromise between sensitivity and specificity and were set at -2.0 for TBS, -0.3 for LS-BMD, -0.2 for TH-BMD and -0.6 for FN-BMD (expressed as Z-scores).

\begin{tabular}{lllc}
\hline Parameters of HPA axis activity & $\begin{array}{l}\text { Sensi- } \\
\text { tivity }\end{array}$ & $\begin{array}{l}\text { Speci- } \\
\text { ficity }\end{array}$ & Accuracy \\
\hline Low TBS & 75 & 61.5 & 67.4 \\
Low LS-BMD & 75 & 30.8 & 50 \\
Low TH-BMD & 72.5 & 44.2 & 56.5 \\
Low FN-BMD & 70 & 50 & 58.7 \\
Low TBS plus low LS-BMD & 60 & 67.3 & 64 \\
Low TBS plus low TH-BMD & 47.5 & 80.8 & 66.3 \\
Low TBS plus low FN-BMD & 52.5 & 86.5 & 71.7 \\
Low TBS plus low BMD at any site & 62.5 & 65.4 & 64 \\
Low TBS or low LS-BMD & 90 & 25 & 53.3 \\
Low TBS or low TH-BMD & 95 & 23.1 & 54.3 \\
Low TBS or low FN-BMD & 95 & 28.8 & 57.6 \\
\hline
\end{tabular}

TBS, trabecular bone score; LS, lumbar spine; TH, total hip; FN, femora neck; BMD, bone mineral density.

$P=0.13$ and $\mathrm{FN}-0.8 \pm 1.4$ vs $0.4 \pm 0.9$ respectively, $P=0.14)$. The subjects with new VFx had no VFx at baseline. They were younger $(64.3 \pm 2.4$ years $)$ and had similar BMI $\left(28.1 \pm 2.4 \mathrm{~kg} / \mathrm{m}^{2}\right)$, urinary calcium $24 \mathrm{~h} / \mathrm{kg} \quad(0.08 \pm 0.03 \mathrm{mmol} /$ day $)$, serum calcium $(2.6 \pm 0.07 \mathrm{mmol} / \mathrm{l})$ and PTH $(129.3 \pm 62.9 \mathrm{ng} / \mathrm{l})$ levels compared with the seven patients without new VFx (age 78.6 \pm 4 years, $P<0.0001$; BMI $27.5 \pm 3.7 \mathrm{~kg} / \mathrm{m}^{2}, P=0.816$; urinary calcium $24 \mathrm{~h} / \mathrm{kg}$ $0.09 \pm 0.04 \mathrm{mmol} /$ day, $\quad P=0.353 ;$ serum calcium $2.6 \pm 0.1 \mathrm{mmol} / \mathrm{l}, P=0.793$ and PTH $108.7 \pm 49.2 \mathrm{ng} / \mathrm{l}$, $P=0.588$ ). The prevalence of co-morbidities (i.e. diabetes mellitus, hypertension and cardiovascular disease) was similar between these two groups (data not shown).

\section{Discussion}

The aim of this study was to evaluate the usefulness of TBS alone or in combination with BMD for predicting VFx in asymptomatic PHPT patients before and after surgery or a conservative follow-up. We found that TBS is reduced in PHPT and correlated with SDI. TBS was associated with VFx regardless of BMD, age, BMI and gender and showed the best accuracy for detecting PHPT subjects with VFx compared with BMD, but the combination low TBS plus low FN-BMD had the best SP and the combination low TBS or low femoral BMD (see Table 2) had the best SN for detecting patients with VFx. After 24 months of follow-up, in surgically treated patients, TBS increased significantly, while in conservatively followed up patients, it tended to decrease. In patients with new VFx of this latter group, TBS decreased more than in those without new fractures, while the BMD changes were comparable.

The data derived from the cross-sectional arm of this study are in keeping with those of a recently published paper of Romagnoli et al. (24), showing that, in PHPT patients, TBS is reduced and more accurate than BMD in detecting patients with VFx. At variance with that study, however, in the present one the years since menopause was not found to be an important parameter to use in combination with TBS to detect patients with fractures. This may be explained by the fact that in this study, but not in the previous one (24), TBS data were adjusted for age and expressed as $Z$ values. This adjustment may probably simplify the clinical use of TBS data. Indeed, the data regarding the diagnostic accuracy (Table 2) suggest that by simply using BMD and TBS, it is possible to find out about the $70 \%$ of PHPT patients with asymptomatic VFx (Fig. 1), with a similar SN and higher SP compared with the study of Romagnoli et al. (24). Overall, these data are of important clinical utility, as by combining BMD and TBS data it could be possible to identify PHPT patients at higher risk to have VFx, even if the high SN (95\%) of the combination low LS-BMD and/or low TBS is obtained at the expense of a low SP (28.8\%) (Fig. 1).

A new finding of this study is the association between TBS and SDI in PHPT patients. This deserves interest as SDI integrates both the number and the severity of VFx $(31,32)$ and this latter parameter has been proposed as a surrogate tool to assess bone quality (33). Therefore, the association between SDI and TBS reinforces the role of TBS as a parameter of bone quality also in PHPT patients, in keeping with recent data showing that, in these patients, TBS correlates with several indices of trabecular micro-architecture (25). However, it is

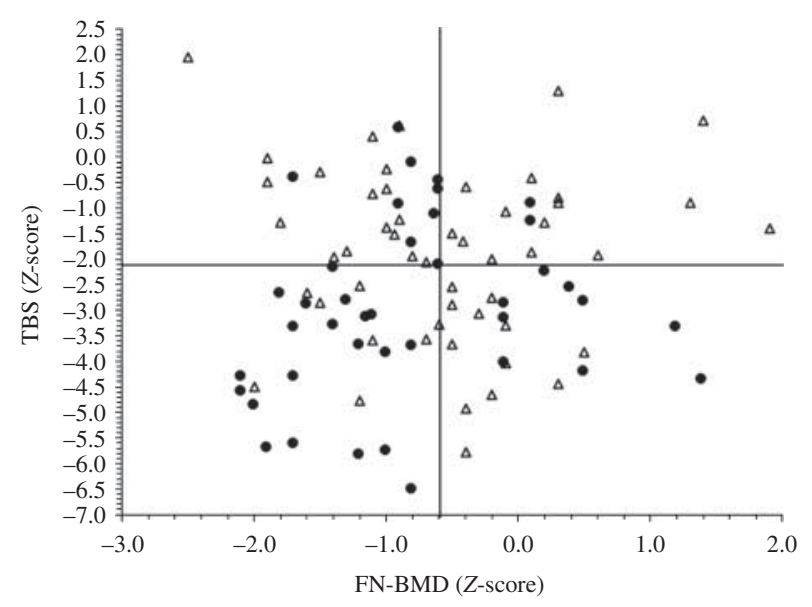

Figure 1 Usefulness of the combination of trabecular bone score (TBS) and femoral neck (FN)-bone mineral density (BMD) (expressed as Z-score) in identifying patients with prevalent asymptomatic vertebral fractures. The dark bars represent the cut-offs for TBS and FN-BMD with the best compromise between sensitivity and specificity obtained by ROC analysis (see text) and set at -2.1 for TBS and -0.6 for BMD (both expressed as $Z$-scores). The presence of the combination low TBS and/or low FN-BMD showed a $95 \%$ SN, but a $28.8 \%$ SP, for detecting patients at risk of fractures (two of the 40 PHPT patients with fractures did not show low TBS and/or low FN-BMD and 37 of the 52 patients without VFx showed low TBS and/or low FN-BMD). Open triangle, patients without fractures; closed circle, patients with fractures. 


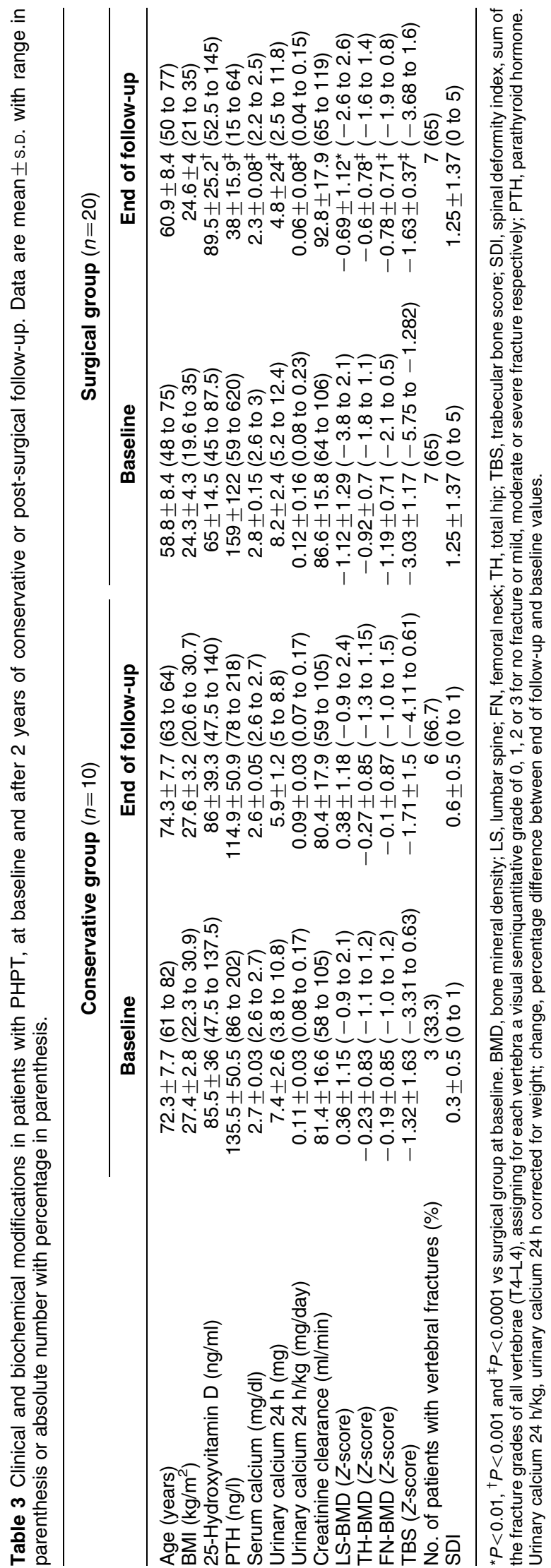

important to note that the risk of VFx in PHPT cannot be attributed to changes in trabecular bone alone, as PTH increases the cortical porosity and the cortical rim accounts for about $40-50 \%$ of vertebral strength (35).

For the first time, the longitudinal data regarding the TBS changes after the recovery from PHPT or after a conservative follow-up are reported (Table 3). The lack of new VFx in surgically treated patients did not allow us to evaluate the possible role of TBS in predicting incident VFx after recovery from PHPT. However, the marked increase in TBS after recovery from PHPT suggests that bone quality, besides bone density, improves after resolution of PTH excess (Fig. 2). This may be explained by the fact that, in the first few months following parathyroidectomy, a positive biochemical uncoupling occurs $(36,37)$, and subsequently, both cortical and trabecular bone turnover normalizes, with a reduction in cortical porosity and an increase in trabecular bone volume $(38,39,40)$. In keeping with this, recent data show that, 1 year after parathyroidectomy in female PHPT patients, cortical bone geometry and cancellous bone architecture improve and cortical and trabecular volumetric BMD in both radius and tibia increase (41).

Conversely, the longitudinal data from the small sample of conservatively followed up patients suggest that bone quality decreases in the presence of persistent PTH excess and reinforce the idea that TBS may have an additive role, besides BMD, in detecting patients at risk of VFx. Indeed, even if the statistical significance was not reached, at variance with BMD values in conservatively followed up subjects, mean TBS levels clearly decreased, particularly in patients with new VFx.

The limits of this study may be related to the relatively small sample of patients and to the absence of controls included in the longitudinal arm of the study (particularly in the conservative group) and to the lack of matching between surgically treated and conservatively followed up patients, with the latter group being older than the former. Moreover, it should be noted that control subjects were recruited from an outpatient clinic and not from population-based controls and that the available TBS normative data are in reference to a different (i.e. French) population (34). However, the changes of TBS in surgically treated PHPT subjects and in those conservatively treated experiencing a new VFx cannot be explained only by the different age and suggest that TBS is useful in predicting the risk of fracture in PHPT patients. Finally, due to budget restriction, we could not measure BMD at the distal $1 / 3$ of the radius that could possibly have been more informative (42). However, in the study of Romagnoli et al. (24), a subgroup of patients underwent a distal 1/3 radius $\mathrm{BMD}$ evaluation, which was not found to be more accurate than TBS in detecting patients with fractures. Overall, compared with the study of Romagnoli et al., we found a similar moderate accuracy of TBS in predicting VFx (AUC 0.73 and 0.74 respectively), while the new 


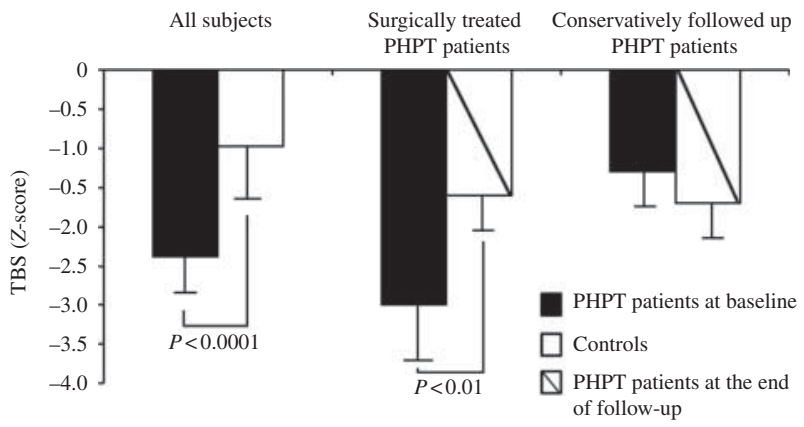

Figure 2 Trabecular bone score (TBS; expressed as Z-scores) in control subjects and in all patients with primary hyperparathyroidism (PHPT) at baseline, in 20 surgically treated patients with PHPT at baseline and after a 24-month follow-up and in 10 conservatively followed up patients with PHPT at baseline and after 24 months.

findings are related to the use of Z-transformed TBS values, which could simplify the clinical use of TBS data, and to the longitudinal evaluation of the TBS changes in patients with PHPT 2 years after the recovery or a conservative follow-up.

Notwithstanding its limits, this study deserves clinical interest, as it shows that with the combined use of TBS and FN-BMD, the 70\% of PHPT patients with VFx can be detected and that in the conservatively followed up PHPT patients, an important decrease in TBS values could predict the occurrence of a VFx, in spite of the absence of a clear BMD decrease.

In conclusion, our study shows that in PHPT: i) TBS is reduced and associated with VFx regardless of BMD, age or years since menopause, BMI and gender; ii) TBS has higher diagnostic accuracy than BMD and may be used together with BMD for identifying patients at risk of VFx; and iii) after recovery TBS increases, while it seems to decrease after a conservative follow-up in patients experiencing new VFx.

Large cross-sectional and longitudinal intervention studies are needed to assess the possible use of TBS in the routine clinical practice for patients with PHPT.

\section{Declaration of interest}

The authors declare that there is no conflict of interest that could be perceived as prejudicing the impartiality of the research reported.

\section{Funding}

This research did not receive any specific grant from any funding agency in the public, commercial or not-for-profit sector.

\section{Author contribution statement}

C Eller-Vainicher and I Chiodini were involved in study design. I Chiodini, V Morelli and S Palmieri were involved in study conduct. C Eller-Vainicher, M Filopanti, U Verga, V V Zhukouskaya, E Cairoli, F M Ulivieri, R Pino and A Naccarato were involved in data collection. C Eller-Vainicher, I Chiodini and A Scillitani were involved in data analysis. C Eller-Vainicher, A Scillitani, I Chiodini and P Beck-Peccoz were involved in data interpretation. C Eller-Vainicher and I Chiodini were involved in drafting the manuscript. P Beck-Peccoz and A Scillitani were involved in revising the manuscript content. C Eller-Vainicher, M Filopanti, V Morelli, F M Ulivieri, R Pino, A Naccarato, S Palmieri, V V Zhukouskaya, E Cairoli, U Verga, A Scillitani, P Beck-Peccoz and I Chiodini were involved in approving the final version of the manuscript. CEller-Vainicher and I Chiodini take the responsibility for the integrity of the data analysis.

\section{References}

1 Melton LJ III. Epidemiology of primary hyperparathyroidism. Journal of Bone and Mineral Research 19956 25-30. (doi:10.1002/ jbmr.5650061409)

2 Lundgren E, Rastad J, Thurfjell E, Akerstrom G \& Ljunghall S. Population-based screening for primary hyperparathyroidism with serum calcium and parathyroid hormone values in menopausal women. Surgery 1997121 287-294. (doi:10.1016/S0039-6060 (97)90357-3)

3 Mosekilde L. Primary hyperparathyroidism and the skeleton. Clinical Endocrinology 200869 1-19. (doi:10.1111/j.1365-2265. 2007.03162.x)

4 Larsson K, Ljunghall S, Krusemo UB, Naessen T, Lindh E \& Persson I. The risk of hip fractures in patients with primary hyperparathyroidism: a population-based cohort study with a follow-up of 19 years. Journal of Internal Medicine 1993234 585-593. (doi:10.1111/j.1365-2796.1993.tb01017.x)

5 Khosla S, Melton LJ III, Wermers RA, Crowson CS, O'Fallon WM \& Riggs BL. Primary hyperparathyroidism and the risk of fracture: a population-based study. Journal of Bone and Mineral Research 1994 14 1700-1707. (doi:10.1359/jbmr.1999.14.10.1700)

6 Vestergaard P, Mollerup CL, Frøkjaer VG, Christiansen P, Blichert-Toft M \& Mosekilde L. Cohort study of risk of fracture before and after surgery for primary hyperparathyroidism. BMJ 2000321 598-602. (doi:10.1136/bmj.321.7261.598)

7 Dempster DW, Parisien M, Silverberg SJ, Liang X-G, Schnitzer M, Shen V, Kimmel DB, Recker R, Lindsay R \& Bilezikian JP. On the mechanism of cancellous bone preservation in postmenopausal women with mild primary hyperparathyroidism. Journal of Clinical Endocrinology and Metabolism 1999840 1562-1566. (doi:10.1210/jc.84.5.1562)

8 De Geronimo S, Romagnoli E, Diacinti D, D’Erasmo E \& Minisola S. The risk of fractures in postmenopausal women with primary hyperparathyroidism. European Journal of Endocrinology 2006155 415-420. (doi:10.1530/eje.1.02225)

9 Vignali E, Viccica G, Diacinti D, Cetani F, Cianferotti L, Ambrogini E, Banti C, Del Fiacco R, Bilezikian JP, Pinchera A et al. Morphometric vertebral fractures in postmenopausal women with primary hyperparathyroidism. Journal of Clinical Endocrinology and Metabolism 200994 2306-2312. (doi:10.1210/jc.2008-2006)

10 Bilezikian JP. Bone strength in primary hyperparathyroidism. Osteoporosis International $2003 \mathbf{1 4}$ S113-S115. (doi:10.1007/ s00198-003-1482-4)

11 Thomsen JS, Ebbesen EL \& Mosekilde L. Predicting human vertebral bone strength by vertebral static histomorphometry. Bone 2002 30 502-508. (doi:10.1016/S8756-3282(01) 00702-5)

12 Patsch JM, Burghardt AJ, Kazakia G \& Majumdar S. Noninvasive imaging of bone microarchitecture. Annals of the New York Academy of Sciences 20111240 77-87. (doi:10.1111/j.1749-6632.2011. 06282.x)

13 Bousson V, Bergot C, Sutter B, Levitz P, Cortet B \& the Scientific Committee of the GRIO (Groupe de Recherche et d'Information sur les Ostéoporoses) . Trabecular bone score (TBS): available knowledge, clinical relevance, and future prospects. Osteoporosis International 201223 1489-1501. (doi:10.1007/s00198-011-1824-6)

14 Hans D, Barthe N, Boutroy S, Pothuaud L, Winzenrieth R \& Krieg MA. Correlations between trabecular bone score, measured using anteroposterior dual energy X-ray absorptiometry acquisition, and 3-dimensional parameters of bone microarchitecture: 
an experimental study on human cadaver vertebrae. Journal of Clinical Densitometry 201114 302-312. (doi:10.1016/j.jocd. 2011.05.005)

15 Pothuaud L, Carceller P \& Hans D. Correlations between grey-level variations in 2D projection images (TBS) and 3D microarchitecture: applications in the study of human trabecular bone microarchitecture. Bone 200842 775-787. (doi:10.1016/j.bone.2007.11.018)

16 Pothuaud L, Barthe N, Krieg MA, Mehsen N, Carceller P \& Hans D. Evaluation of the potential use of trabecular bone score to complement bone mineral density in the diagnosis of osteoporosis: a preliminary spine BMD-matched, case-control study. Journal of Clinical Densitometry 200912 170-176. (doi:10.1016/j.jocd.2008.11.006)

17 Rabier B, Héraud A, Grand-Lenoir C, Winzenrieth R \& Hans D. A multicentre, retrospective case-control study assessing the role of trabecular bone score (TBS) in menopausal Caucasian women with low areal bone mineral density (BMDa): analysing the odds of vertebral fracture. Bone 201046 176-181. (doi:10.1016/j.bone.2009.06.032)

18 Winzenrieth R, Dufour R, Pothuaud L \& Hans D. A retrospective case-control study assessing the role of trabecular bone score in postmenopausal Caucasian women with osteopenia: analyzing the odds of vertebral fracture. Calcified Tissue International $2010 \mathbf{8 6}$ 104-109. (doi:10.1007/s00223-009-9322-y)

19 Hans D, Goertzen AL, Krieg MA \& Leslie WD. Bone microarchitecture assessed by TBS predicts osteoporotic fractures independent of bone density; the Manitoba Study. Journal of Bone and Mineral Research 200126 2762-2769. (doi:10.1002/jbmr.499)

20 Del Rio LM, Winzenrieth R, Cormier C \& Di Gregorio S. Is bone microarchitecture status of the lumbar spine assessed by TBS related to femoral neck fracture? A Spanish case-control study Osteoporosis International 201324 991-998. (doi:10.1007/ s00198-012-2008-8)

21 Breban S, Briot K, Kolta S, Paternotte S, Ghazi M, Fechtenbaum J \& Roux C. Identification of rheumatoid arthritis patients with vertebral fractures using bone mineral density and trabecular bone score. Journal of Clinical Densitometry 201215 260-266. (doi:10.1016/j.jocd.2012.01.007)

22 Eller-Vainicher C, Morelli V, Ulivieri FM, Palmieri S, Zhukouskaya VV, Cairoli E, Pino R, Naccarato A, Scillitani A, Beck-Peccoz P et al. Bone quality, as measured by trabecular bone score (TBS), in patients with adrenal incidentalomas with and without subclinical hypercortisolism. Journal of Bone and Mineral Research 201227 2223-2230. (doi:10.1002/jbmr.1648)

23 Hofbauer LC, Hamann C \& Ebeling PR. Approach to the patient with secondary osteoporosis. European Journal of Endocrinology 2010162 1009-1020. (doi:10.1530/EJE-10-0015)

24 Romagnoli E, Cipriani C, Nofroni I, Castro C, Angelozzi M, Scarpiello A, Pepe J, Diacinti D, Piemonte S, Carnevale V et al. "Trabecular bone score" (TBS): an indirect measure of bone micro-architecture in postmenopausal patients with primary hyperparathyroidism. Bone 201253 154-159. (doi:10.1016/j.bone.2012.11.041)

25 Silva BC, Boutroy S, Zhang C, McMahon DJ, Zhou B, Wang J, Udesky J, Cremers S, Sarquis M, Guo XD et al. Trabecular bone score (TBS) - a novel method to evaluate bone microarchitectural texture in patients with primary hyperparathyroidism. Journal of Clinical Endocrinology and Metabolism 201398 1963-1970. (doi:10.1210/jc.2012-4255)

26 Eastell R, Arnold A, Brandi ML, Brown EM, D’Amour P, Hanley DA, Rao DS, Rubin MR, Goltzman D, Silverberg SJ et al. Diagnosis of asymptomatic primary hyperparathyroidism: Proceedings of the Third International Workshop. Journal of Clinical Endocrinology and Metabolism 200994 340-350. (doi:10.1210/jc.2008-1758)

27 Eller-Vainicher C, Chiodini I, Battista C, Viti R, Mascia ML, Massironi S, Peracchi M, D'Agruma L, Minisola S, Corbetta S et al. Sporadic and MEN1-related primary hyperparathyroidism: differences in clinical expression and severity. Journal of Bone and Mineral Research 200924 1404-1410. (doi:10.1359/jbmr.090304)

28 Adami S, Romagnoli E, Carnevale V, Scillitani A, Giusti A, Rossini M, Gatti D, Nuti R \& Minisola S. Guidelines on prevention and treatment of vitamin D deficiency. Reumatismo 201163 129-147. (doi:10.4081/reumatismo.2011.129)
29 UpToDate calculator. In Calcium Correction in Hypoalbuminemia, Topic 836 version 7.0. Waltham, MA: Wolters Kluwer-Health, 2013. Available www.uptodate.com.

30 Simonelli C, Adler RA, Blake GM, Caudill JAP, Khan A, Leib E, Maricic M, Prior JC, Eis SR, Rosen C et al. Dual energy X-ray absorptiometry technical Issues: the 2007 ISCD official positions. Journal of Clinical Densitometry 20081 109-122. (doi:10.1016/j. jocd.2007.12.009)

31 Genant HK, Wu CY, van Knijk C \& Nevitt M. Vertebral fracture assessment using a semi-quantitative technique. Journal of Bone and Mineral Research 19938 1137-1148. (doi:10.1002/jbmr. 5650080915)

32 Crans GG, Genant HK \& Krege JH. Prognostic utility of a semiquantitative spinal deformity index. Bone 200537 175179. (doi:10.1016/j.bone.2005.04.003)

33 Genant HK, Delmas PD, Chen P, Jiang Y, Eriksen EF, Dalsky GP, Marcus R \& San Martin J. Severity of vertebral fracture reflects deterioration of bone microarchitecture. Osteoporosis International 200718 69-76. (doi:10.1007/s00198-006-0199-6)

34 Dufour R \& Heraud A. Lumbar spine micro-architecture in French women derived from DXA: TBS normative data; March 11-14, $\mathrm{p}$ 104. Orlando, USA: International Society for Clinical Densitometry 15th Annual Meeting, 2009.

35 Melton LJ III, Riggs BL, Keaveny TM, Achenbach SJ, Kopperdahl D, Camp JJ, Rouleau PA, Amin S, Atkinson EJ, Robb RA et al. Relation of vertebral deformities to bone density, structure, and strength. Journal of Bone and Mineral Research 201025 1922-1930. (doi:10.1002/jbmr.150)

36 Minisola S, Scarnecchia L, Scarda A, Bigi F, Tabolli S, Valtorta C \& Mazzuoli G. Serum osteocalcin in primary hyperparathyroidism: short-term effect of surgery. Mineral and Electrolyte Metabolism 198814 201-207.

37 Minisola S, Romagnoli E, Scarnecchia L, Rosso R, Pacitti MT, Scarda A \& Mazzuoli G. Serum carboxy-terminal propeptide of human type I procollagen in patients with primary hyperparathyroidism: studies in basal conditions and after parathyroid surgery. European Journal of Endocrinology 1994130 587-591. (doi:10.1530/eje.0.1300587)

38 Christiansen P, Steiniche T, Brixen K, Hessov I, Melsen F, Heickendorff L \& Mosekilde L. Primary hyperparathyroidism: short-term changes in bone remodeling and bone mineral density following parathyroidectomy. Bone 199925 237-244. (doi:10.1016/S8756-3282(99)00150-7)

39 Brockstedt H, Christiansen P, Mosekilde L \& Melsen F. Reconstruction of cortical bone remodeling in untreated primary hyperparathyroidism and following surgery. Bone 199516 109-117.

40 Christiansen P, Steiniche T, Mosekilde L, Hessov I \& Melsen F. Primary hyperparathyroidism: changes in trabecular bone remodeling following surgical treatment, evaluated by histomorphometric methods. Bone 199011 75-79. (doi:10.1016/87563282(90)90053-2)

41 Hansen S, Huge EM, Rasmussen L, Beck Jensen J-E \& Brixen K. Parathyroidectomy improves bone geometry and microarchitecture in female patients with primary hyperparathyroidism: a one-year prospective controlled study using high-resolution peripheral quantitative computed tomography. Journal of Bone and Mineral Research 201227 1150-1158. (doi:10.1002/jbmr.1540)

42 Charopoulos I, Tournis S, Trovas G, Raptou P, Kaldrymides P, Skarandavos G, Katsalira K \& Lyritis GP. Effect of primary hyperparathyroidism on volumetric bone mineral density and bone geometry assessed by peripheral quantitative computed tomography in postmenopausal women. Journal of Clinical Endocrinology and Metabolism 200691 1748-1753. (doi:10.1210/jc.2005-2102)

Received 11 April 2013

Revised version received 14 May 2013

Accepted 16 May 2013 